Check for updates

Cite this: RSC Adv., 2017, 7, 54546

Received 28th August 2017

Accepted 21st November 2017

DOI: 10.1039/c7ra09541d

rsc.li/rsc-advances

\section{Enhanced adsorption capacity and selectivity towards strontium ions in aqueous systems by sulfonation of $\mathrm{CO}_{2}$ derived porous carbon $\dagger$}

\begin{abstract}
S. Baik, ${ }^{a}$ H. Zhang, (D) ${ }^{b}$ Y. K. Kim, ${ }^{a}$ D. Harbottle ${ }^{\star b}$ and J. W. Lee (D) *a
Oxygen-enriched carbon materials derived from carbon dioxide were functionalized using sulfonic acid to remove $\mathrm{Sr}^{2+}$ ions from aqueous solutions. Synthesized sulfonated porous carbon materials $\left(\mathrm{PC}-\mathrm{SO}_{3} \mathrm{H}\right)$ showed higher adsorption capacity and selectivity towards $\mathrm{Sr}^{2+}$ than non-functionalized porous carbons (PC). The formation of the $\mathrm{C}-\mathrm{SO}_{3} \mathrm{H}$ functional group in $\mathrm{PC}-\mathrm{SO}_{3} \mathrm{H}$ and its ability to proton exchange with $\mathrm{Sr}^{2+}$ was the main contributor to the enhanced performance. The maximum uptake capacity of $\mathrm{Sr}^{2+}$ by $\mathrm{PC}-\mathrm{SO}_{3} \mathrm{H}$ was $18.97 \mathrm{mg} \mathrm{g}^{-1}$, which was 1.74 times greater than $\mathrm{PC}$. $\mathrm{PC}-\mathrm{SO}_{3} \mathrm{H}$ removed $99.9 \%$ and $97.6 \%$ of $\mathrm{Sr}^{2+}$ from aqueous solutions with initial $\mathrm{Sr}^{2+}$ concentrations of $5 \mathrm{mg} \mathrm{L}^{-1}$ and $10 \mathrm{mg} \mathrm{L}^{-1}$, respectively. $\mathrm{Sr}^{2+}$ adsorption showed rapid kinetics, reaching the adsorption equilibrium within $1 \mathrm{~h}$ with high adsorption capacity at equilibrium which is 3.52 times greater than that of PC. Additionally, $\mathrm{PC}-\mathrm{SO}_{3} \mathrm{H}$ selectively adsorbed $\mathrm{Sr}^{2+}$ even in the presence of excess amounts of competing ions. Sulfonation of oxygen-enriched carbon had a significant effect on enhancing the affinity towards $\mathrm{Sr}^{2+}$ and suppressing adsorption towards other competing ions.
\end{abstract}

\section{Introduction}

Nuclear power is considered a promising candidate to satisfy the increased demand for energy. Currently nuclear power accounts for $4.8 \%$ of the world's total energy supply, and the proportion of energy supplied by nuclear is anticipated to grow. ${ }^{1,2}$ However, radioactive waste from nuclear power can cause long-term environmental and health threats. In particular, ${ }^{89} \mathrm{Sr}$ and ${ }^{90} \mathrm{Sr}$ are radioactive isotopes which are present in nuclear reactors and various forms of nuclear waste, ${ }^{3}$ and if released into the environment (e.g. nuclear incidents such as Chernobyl and Fukushima), ${ }^{89} \mathrm{Sr}$ and ${ }^{90} \mathrm{Sr}$ can present a significant public health risk following exposure to the radioactivity. ${ }^{4,5}$ Furthermore, strontium exhibits a long half-life (28.8 years) and a high decay energy; therefore effective ways to treat strontium $\left(\mathrm{Sr}^{2+}\right)$ contaminated environments must be considered. ${ }^{6}$

Adsorption is often considered a feasible and somewhat economical method for the recovery of radioactive isotopes from liquid wastes. ${ }^{7-10}$ Numerous studies have considered the removal of $\mathrm{Sr}^{2+}$ from aqueous environments using various adsorbents. Clay minerals such as kaolinite ${ }^{11}$ and attapulgite ${ }^{12}$

${ }^{a}$ Department of Chemical and Biomolecular Engineering, Korea Advanced Institute of Science and Technology (KAIST), 291 Daehak-ro (373-1 Guseong-dong), Yuseong-gu, Daejeon 34141, Republic of Korea. E-mail: jaewlee@kaist.ac.kr

${ }^{b}$ School of Chemical and Process Engineering, University of Leeds, Leeds LS2 9JT, UK. E-mail: D.Harbottle@leeds.ac.uk

$\dagger$ Electronic supplementary information (ESI) available: SEM images, BET measurements details. See DOI: 10.1039/c7ra09541d were frequently studied due to its large edge surface and high ability for ion exchange which is common and effective mechanism for adsorption in aqueous systems. ${ }^{13,14}$ Along with the ability for ion exchange, the porous structure is usually favored when designing effective adsorbents. ${ }^{15-17}$ Therefore, studies moves onto various materials with those characteristics such as zeolite, ${ }^{18}$ silica, ${ }^{19,20}$ titanosilicate, ${ }^{21}$ Prussian blue, ${ }^{22}$ and titanate nanotubes. ${ }^{23}$

While carbon exhibits the right physical properties along with low cost and its abundance, removal performance of $\mathrm{Sr}^{2+}$ is poor with carbon-based adsorbents exhibiting low removal efficiencies below $70 \%$ (ref. 24-26) and low selectivity for $\mathrm{Sr}^{2+} \cdot{ }^{27,28}$ Research to improve the adsorption properties of carbon-based materials, especially the removal of $\mathrm{Sr}^{2+}$, has been limited but is the focus of this study.

In the current study, carbon dioxide $\left(\mathrm{CO}_{2}\right)$-derived porous carbon materials have been functionalized with sulfonic acid to enhance removal of $\mathrm{Sr}^{2+}$. The sulfonic acid groups have been identified to improve the removal efficiency of heavy metal ions such as cadmium, ${ }^{29}$ lead $^{30}$ and uranium, ${ }^{31}$ but there is no evidence relating to strontium adsorption. Recently, Aguila et $\mathrm{al}^{32}$ reported a metal organic framework (MOF)- $\mathrm{SO}_{3} \mathrm{H}$ for the removal of $\mathrm{Sr}^{2+}$. The authors suggested the possibility of cation exchange between the proton in $\mathrm{SO}_{3} \mathrm{H}$ and $\mathrm{Sr}^{2+}$, but experimental confirmation of this hypothesis was not provided. To the best of our knowledge, this is the first study to confirm the effect of $\mathrm{SO}_{3} \mathrm{H}$ functional group for improved $\mathrm{Sr}^{2+}$ removal from aqueous systems. The reaction to functionalize the carbon backbone with $\mathrm{SO}_{3} \mathrm{H}$ groups is demonstrated and 
supplemented with detailed material characterization. Various comparative adsorption studies between the sulfonated porous carbon and non-functionalized porous carbon were investigated to highlight the performance characteristics of $\mathrm{SO}_{3} \mathrm{H}$ groups, specifically $\mathrm{Sr}^{2+}$ adsorption, with the mechanism for ion exchange clearly demonstrated and discussed.

\section{Experimental}

\section{Materials}

Sodium borohydride $\left(\mathrm{NaBH}_{4},>96 \%\right)$, hydrochloric acid ( $\mathrm{HCl}$, $37 \mathrm{wt} \%$ ), strontium standard solution (1000 $\mathrm{mg} \mathrm{L}^{-1}$, for AAS), sodium chloride $(\mathrm{NaCl},>99 \%)$ and seawater whose cations composition was $10409 \mathrm{ppm} \mathrm{Na}^{+}, 359 \mathrm{ppm} \mathrm{K}$, $1327 \mathrm{ppm} \mathrm{Mg}^{2+}$ and $176 \mathrm{ppm} \mathrm{Ca}^{2+}$ (ref. 33) were purchased from Sigma-Aldrich. Concentrated sulfuric acid $\left(\mathrm{H}_{2} \mathrm{SO}_{4}, 95-98 \%\right)$ and potassium chloride (KCl, 99.9\%) were obtained from Fluka. $\mathrm{CO}_{2}$ used to prepare the carbon particles and acetylene and $\mathrm{N}_{2} \mathrm{O}(>99.8 \%)$ for the atomic adsorption spectrometry were supplied by BOC gas. All chemicals were used without further purification. Ultrapure Milli-Q water (distilled water, DIW) with a resistivity of $18.2 \mathrm{M} \Omega \mathrm{cm}$ was used in all experiments.

\section{Preparation of porous carbon (PC) from $\mathrm{CO}_{2}$}

The procedure to form the $\mathrm{CO}_{2}$-derived porous carbon was adopted from earlier studies. ${ }^{34-37} 5 \mathrm{~g}$ of $\mathrm{NaBH}_{4}$ powder was loaded into a steel-alloy tube and the tube was placed inside the furnace (MTF 12/25/400, Carbolite Gero Ltd.). The powder was heated to $500{ }^{\circ} \mathrm{C}$ from room temperature at a heating rate of $5{ }^{\circ} \mathrm{C} \min ^{-1}$. The sample was then held at this temperature for $2 \mathrm{~h}$, before natural convection cooling to room temperature under a continuous flow of $\mathrm{CO}_{2}$ at $100 \mathrm{~mL} \mathrm{~min}{ }^{-1}$. The solid product $\left(\mathrm{CO}_{2}\right.$-derived porous carbon (PC)) was then washed with $1 \mathrm{M} \mathrm{HCl}$ at $50{ }^{\circ} \mathrm{C}$ for $30 \mathrm{~min}$ while stirring the suspension at $300 \mathrm{rpm}$ to remove any unreacted $\mathrm{NaBH}_{4}$ and other impurities. The product was washed with DIW for $15 \mathrm{~min}$ and filtered. The wash and filtration processes were repeated further five times until the $\mathrm{pH}$ of the wash water was above $\mathrm{pH}$ 5.5. Finally, the product underwent 15 min washing in ethanol before evaporating the ethanol in air for $6 \mathrm{~h}$ at $100{ }^{\circ} \mathrm{C}$.

\section{Attachment of sulfonic acid functional group to porous carbon $\left(\mathrm{PC}_{-} \mathrm{SO}_{3} \mathrm{H}\right)$}

$1 \mathrm{~g}$ of the prepared PC was dispersed in $20 \mathrm{~mL}$ of $\mathrm{H}_{2} \mathrm{SO}_{4}$. The mixture was heated to $130{ }^{\circ} \mathrm{C}$ in an oil bath and held at a constant temperature for $15 \mathrm{~h}$ while gently stirring the suspension at $200 \mathrm{rpm}$ using a magnetic stirrer. Following the hydrothermal treatment the sample was cooled to room temperature and diluted in DIW and then filtered using filter paper (grade 1). Following the filtration the product was washed with DIW for 15 min and subsequently filtered. The wash and filtration processes using DIW were once again repeated until the $\mathrm{pH}$ exceeded 5. Finally, the product (sulfonated porous carbon $\left(\mathrm{PC}-\mathrm{SO}_{3} \mathrm{H}\right)$ ) was air dried for $24 \mathrm{~h}$ at $120{ }^{\circ} \mathrm{C}$.

\section{Characterization}

Elemental analysis was conducted using a CHNS/O elemental analyzer (Thermo Fisher Scientific, Flash 2000). Fourier transform infrared (FTIR) spectra were collected using the Thermo Fisher Scientific Nicolet iS10 with an attenuated total reflection (ATR) accessory. X-ray photoelectron spectroscopy (XPS) data were acquired using a multi-purpose XPS device (Thermo Fisher Scientific, Sigma Probe) equipped with an MXR1 gun (400 $\mu \mathrm{m})$. Scanning electron microscopy (SEM) images and energy dispersive spectroscopy (EDS) data were obtained using a field emission SEM (FEI Company, Magellan 400). Prior to the measurement (XPS and SEM) the powder samples were deposited onto a carbon tape. The nitrogen adsorption/desorption isotherms at $77 \mathrm{~K}$ were obtained using a Micromeritics 3Flex. The surface area for $\mathrm{PC}$ and $\mathrm{PC}-\mathrm{SO}_{3} \mathrm{H}$ was calculated according to the Brunauer-Emmett-Teller (BET) method, and the pore size distribution was determined from a non-local density functional theory (NLDFT) method.

\section{Strontium adsorption experiments}

To determine the equilibrium adsorption capacity of the formed products, a $\mathrm{Sr}^{2+}$ adsorption isotherm was constructed by measuring the $\mathrm{Sr}^{2+}$ uptake at a range of initial $\mathrm{Sr}^{2+}$ concentrations. The initial $\mathrm{Sr}^{2+}$ concentrations $(1,5,10,20,50,100,200$ and $350 \mathrm{mg} \mathrm{L}^{-1}$ ) were determined by diluting a stock solution (1000 $\mathrm{mg} \mathrm{L}^{-1}$ ) using DIW. $20 \mathrm{mg}$ of the powdered sample was added to $20 \mathrm{~mL}$ of each $\mathrm{Sr}^{2+}$ solution (solid to liquid ratio = $1 \mathrm{~g} \mathrm{~L}^{-1}$ ), and the suspension was shaken for $24 \mathrm{~h}$ at room temperature using an orbital shaker.

For the adsorption kinetic test the initial $\mathrm{Sr}^{2+}$ concentration was fixed at $20 \mathrm{mg} \mathrm{L}^{-1}$ and the suspension $\left(1 \mathrm{~g} \mathrm{~L}^{-1}\right)$ was shaken at room temperature for $0.17,0.33,0.66,1,2,3$ and $5 \mathrm{~h}$. For both isotherm and kinetic studies, following $\mathrm{Sr}^{2+}$ adsorption, the suspension was centrifuged at $11000 \mathrm{rpm}$ for $15 \mathrm{~min}$ and the supernatant was recovered and filtered using a $0.45 \mu \mathrm{m}$ syringe filter. The $\mathrm{Sr}^{2+}$ concentration remaining in the supernatant was quantified using a fast sequential atomic absorption spectrometer (AAS, VARIAN AA240FS).

\section{Results \& discussion}

\section{Structural analysis for synthesized $\mathrm{PC}^{-\mathrm{SO}_{3} \mathrm{H}}$}

The chemical composition of the synthesized $\mathrm{PC}^{-} \mathrm{SO}_{3} \mathrm{H}$ measured by elemental analyzer (EA) is shown in Table 1. Sulfur and oxygen contents were shown to increase following the sulfonation of PC even though the observed sulfur composition is a bit lower than its expected value. This suggests that the sulfonic acid groups are chemically bound to the carbon surface in the $\mathrm{PC}-\mathrm{SO}_{3} \mathrm{H}$ as intended.

Attachment of the sulfonic acid groups to the PC was verified from the FTIR spectra as shown in Fig. 1. The peak at $550 \mathrm{~cm}^{-1}$ can be assigned to the $\mathrm{C}-\mathrm{S}$ stretch ${ }^{38}$ and the peak at $1059 \mathrm{~cm}^{-1}$ corresponds to the $\mathrm{SO}_{3}{ }^{-}$stretch. ${ }^{39}$ Peaks at $1154 \mathrm{~cm}^{-1}$ and $1200 \mathrm{~cm}^{-1}$ confirm the existence of $\mathrm{SO}_{2}$ related bonds while the peaks are slightly shifted (higher wave numbers) when compared to the literature values. ${ }^{\mathbf{4 0 , 4 1}}$ This shift was also 
Table 1 Chemical compositions of $\mathrm{PC}$ and $\mathrm{PC}-\mathrm{SO}_{3} \mathrm{H}$ measured by the elemental analyzer (CHNS/O)

\begin{tabular}{llllll}
\hline & $\mathrm{PC}$ & & \multicolumn{2}{l}{${\mathrm{PC}-\mathrm{SO}_{3} \mathrm{H}}$} & \\
\cline { 5 - 6 } Expected $^{a}$ & Observed & & Expected $^{a}$ & Observed \\
\hline $\mathrm{C}$ & $74 \%$ & $76.89 \%$ & & $65.26 \%$ & $65.73 \%$ \\
$\mathrm{H}$ & $2 \%$ & $2.51 \%$ & & $0.21 \%$ & $2.13 \%$ \\
$\mathrm{~N}$ & - & $0.20 \%$ & & $0.17 \%$ & $0.19 \%$ \\
$\mathrm{~S}$ & - & - & & $6.82 \%$ & $1.77 \%$ \\
$\mathrm{O}$ & $17 \%$ & $15.44 \%$ & & $23.33 \%$ & $25.93 \%$
\end{tabular}

${ }^{a}$ The expected chemical composition of PC is averaged value from previous studies, ${ }^{34,37}$ and that of $\mathrm{PC}^{-} \mathrm{SO}_{3} \mathrm{H}$ is determined based on the assumption that $10 \%$ of $\mathrm{C}-\mathrm{H}$ bonds in $\mathrm{PC}$ are replaced by $\mathrm{C}-\mathrm{SO}_{3} \mathrm{H}$ bonds.

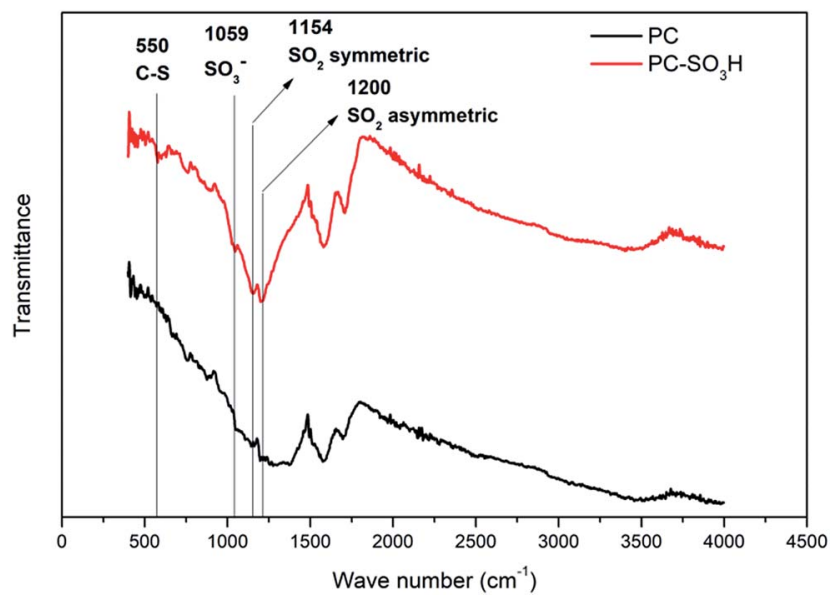

Fig. 1 FTIR spectra and peak assignments of $\mathrm{PC}-\mathrm{SO}_{3} \mathrm{H}$ including $\mathrm{PC}$ as reference.

reported from the previous studies for sulfonic acid-treated carbon materials. ${ }^{38,42}$ The remaining peaks in the spectra can be assigned to either $\mathrm{C}-\mathrm{O}$ or $\mathrm{C}-\mathrm{B}$, which are observed in both $\mathrm{PC}$ and $\mathrm{PC}-\mathrm{SO}_{3} \mathrm{H}$ samples that are synthesized from $\mathrm{CO}_{2} \cdot{ }^{35-37} \mathrm{It}$ should be noted that the presence of both $\mathrm{C}-\mathrm{S}$ and $\mathrm{S}-\mathrm{O}$ bonds in

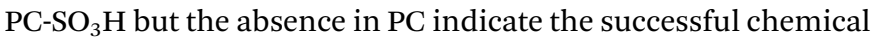
bonding of sulfonic acid group to the carbon in $\mathrm{PC}_{-} \mathrm{SO}_{3} \mathrm{H}$.

The surface elemental composition of the two samples was confirmed by XPS. From the data, PC contained $82.93 \%$ carbon, $13.74 \%$ oxygen and $3.34 \%$ boron, with the composition changing to $78.36 \%$ carbon, $17.54 \%$ oxygen, $1.84 \%$ boron and

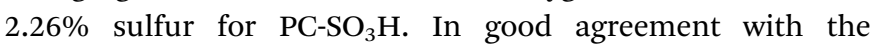
elemental compositions shown in Table 1, the sulfonation of PC increased both the oxygen and sulfur content in $\mathrm{PC}^{-} \mathrm{SO}_{3} \mathrm{H}$. The slight increase in sulfur content when measured by XPS compared to EA suggests that the sulfur atoms are enriched on the surface of carbon. To better understand the nature of the chemical bonds in PC and $\mathrm{PC}-\mathrm{SO}_{3} \mathrm{H}$, deconvolution of the $\mathrm{C} 1 \mathrm{~s}$, $\mathrm{O} 1 \mathrm{~s}, \mathrm{~S} 2 \mathrm{p}$ and B 1s spectra was conducted. As shown in the $\mathrm{C} 1 \mathrm{~s}$ spectra of PC (Fig. 2(a)), the three peaks can be assigned to $\mathrm{C}=\mathrm{C}$ $(283.6 \mathrm{eV}), \mathrm{C}-\mathrm{C}(285.2 \mathrm{eV})$ and $\mathrm{C}=\mathrm{O}(288.5 \mathrm{eV}),{ }^{43-48}$ while the additional peak observed in the $\mathrm{C} 1 \mathrm{~s}$ spectra of $\mathrm{PC}^{-} \mathrm{SO}_{3} \mathrm{H}$
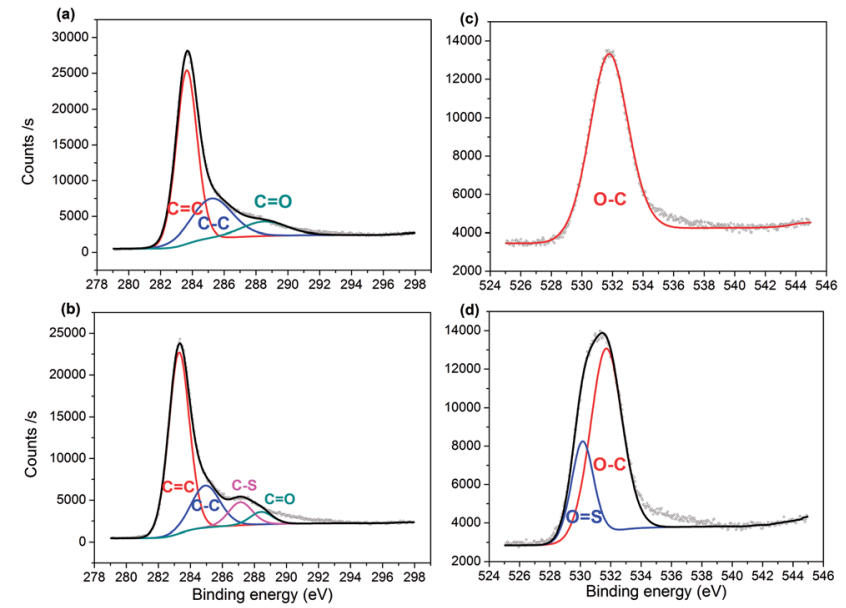

Fig. 2 XPS spectra of $\mathrm{C}$ 1s peaks for (a) $\mathrm{PC}$ and (b) $\mathrm{PC}-\mathrm{SO}_{3} \mathrm{H}$, respectively; and $\mathrm{O}$ 1s peaks for (c) $\mathrm{PC}$ and (d) $\mathrm{PC}-\mathrm{SO}_{3} \mathrm{H}$.

(Fig. 2(b)) corresponds to C-S bonds $(287.1 \mathrm{eV}){ }^{44,46,49}$ Deconvolution of the $\mathrm{O} 1 \mathrm{~s}$ spectra is shown in Fig. 2(c) and (d). A main peak centered at $531.7 \mathrm{eV}$ is attributed to the $\mathrm{O}-\mathrm{C}$ group, and a second peak observed for $\mathrm{PC}_{-} \mathrm{SO}_{3} \mathrm{H}$ can be assigned to $\mathrm{O}=\mathrm{S}$

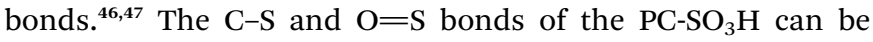
clearly identified through the deconvolution of the XPS spectra

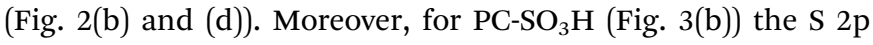
peak centered at $167.4 \mathrm{eV}$ corresponds to $\mathrm{C}-\mathrm{S}-\mathrm{O}$ bonds, ${ }^{43,45,50}$ which is absent for PC. Deconvolution of the B 1s spectra confirmed no changes following the sulfonation step, as shown in Fig. 3(c) and (d). As such, it is reasonable to state that the sulfur atoms bind to the carbon and oxygen atoms and not the boron atoms. Hence, the majority of the sulfur exists in the form of $\mathrm{C}-\mathrm{S}-\mathrm{O}$, which is present in the $\mathrm{C}-\mathrm{SO}_{3} \mathrm{H}$ functional group.

Chemical composition and elemental mapping was determined by SEM-EDS (Fig. 4 and $\mathrm{S} 1 \dagger$ ). For $\mathrm{PC}^{-\mathrm{SO}_{3} \mathrm{H}}$ the composition profile (Fig. 4(a)) was shown to be $69.73 \%$ carbon, $26.33 \%$
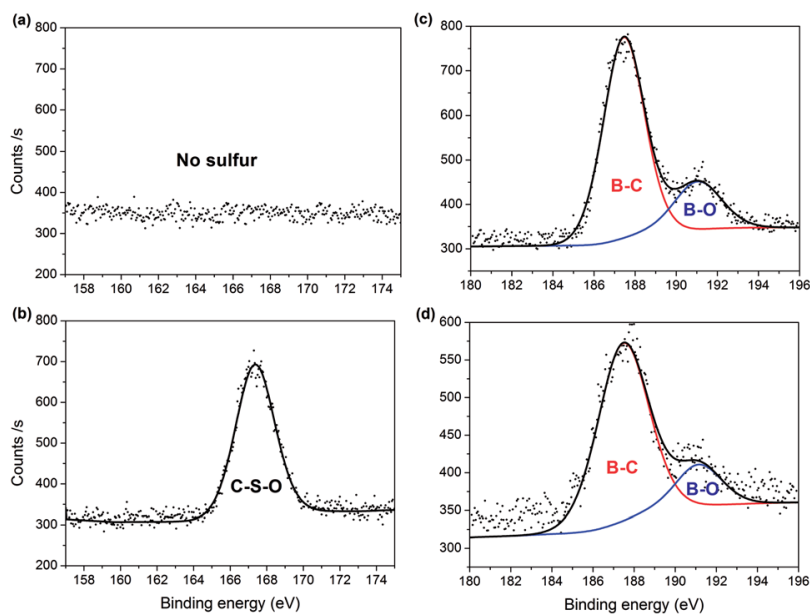

Fig. 3 XPS spectra showing: absence and presence of $\mathrm{S} 2 \mathrm{p}$ peaks in (a) $\mathrm{PC}$ and (b) $\mathrm{PC}-\mathrm{SO}_{3} \mathrm{H}$, respectively; and $\mathrm{B}$ 1s peaks for (c) PC and (d) $\mathrm{PC}-\mathrm{SO}_{3} \mathrm{H}$. 


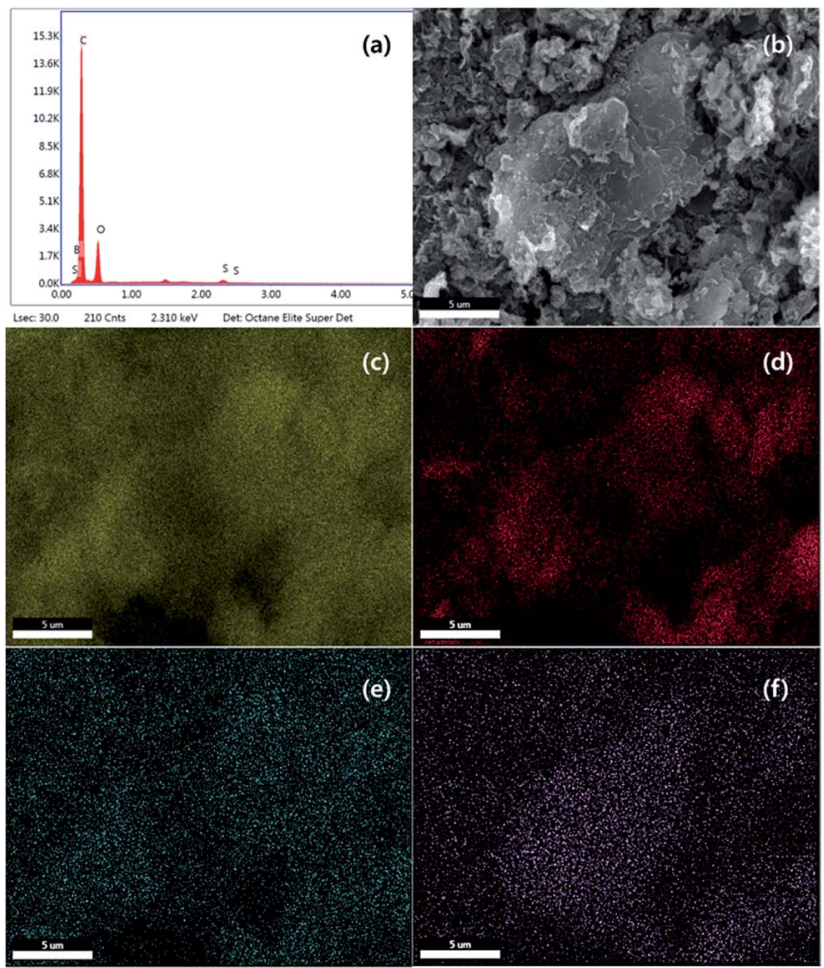

Fig. 4 SEM-EDS (a) composition profile, (b) image, (c) carbon map, (d) oxygen map, (e) boron map and (f) sulfur map for $\mathrm{PC}-\mathrm{SO}_{3} \mathrm{H}$.

oxygen, $1.39 \%$ boron and $2.56 \%$ sulfur, which is in excellent agreement with the composition determined by EA shown in Table 1. Elemental maps in Fig. 4(b-f) show that all atoms including sulfur are uniformly distributed and dispersed across the carbon surface. Although $\mathrm{PC}^{-\mathrm{SO}_{3} \mathrm{H}}$ shows porous morphology similar to PC in SEM images (Fig. S1†), the specific BET surface area decreased after sulfonation (Table S1 $\dagger$ ). Both isotherm curve and pore size distribution (Fig. S2 $\dagger$ ) indicate the collapse of pores by sulfuric acid, which may be the reason why specific surface area was reduced.

\section{Strontium ion adsorption}

The $\mathrm{Sr}^{2+}$ adsorption capacity of $\mathrm{PC}$ and $\mathrm{PC}-\mathrm{SO}_{3} \mathrm{H}$ was determined by fitting the equilibrium adsorption data to the Langmuir-isotherm model:

$$
Q_{\mathrm{e}}=\frac{Q_{\mathrm{m}} b C_{\mathrm{e}}}{1+b C_{\mathrm{e}}}
$$

where $Q_{\mathrm{e}}\left(\mathrm{mg} \mathrm{g}^{-1}\right)$ is the equilibrium adsorption, $Q_{\mathrm{m}}\left(\mathrm{mg} \mathrm{g}^{-1}\right)$ is the theoretical maximum adsorption capacity, $b\left(\mathrm{~L} \mathrm{mg}^{-1}\right)$ is the Langmuir constant which represents the affinity between $\mathrm{Sr}^{2+}$ and the adsorbent, and $C_{\mathrm{e}}\left(\mathrm{mg} \mathrm{L}^{-1}\right)$ is the ionic concentration at equilibrium. Fig. 5 shows the amount of $\mathrm{Sr}^{2+}$ adsorbed as a function of the equilibrium concentration, with the data fitted using eqn (1). It shows good agreement between the experimental data and the Langmuir model for both $\mathrm{PC}$ and $\mathrm{PC}-\mathrm{SO}_{3} \mathrm{H}$. Based on the isotherm fitting parameters (Table 2), the maximum adsorption capacity of $\mathrm{PC}-\mathrm{SO}_{3} \mathrm{H}$ is 1.74 times higher

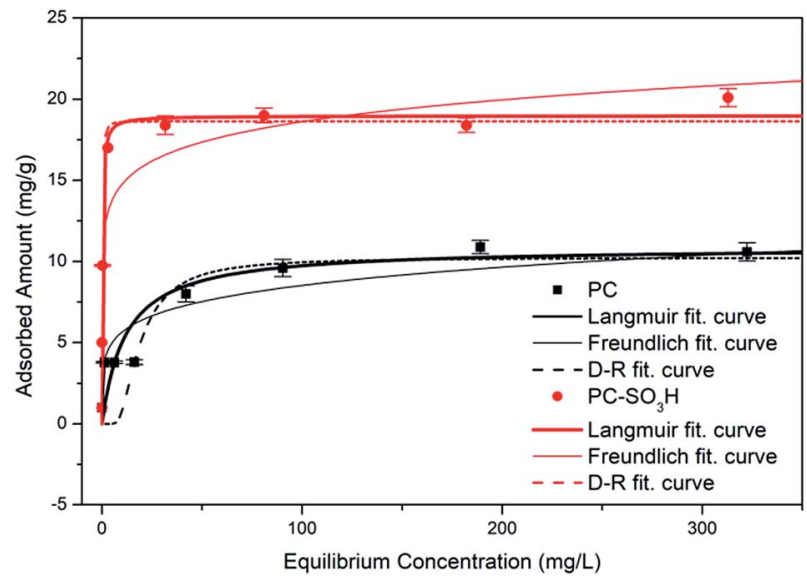

Fig. 5 Adsorption isotherms of $\mathrm{Sr}^{2+}$ onto $\mathrm{PC}$ and $\mathrm{PC}-\mathrm{SO}_{3} \mathrm{H}$ with fitted Langmuir, Freundlich, and Dubinin-Radushkevich isotherm curves.

Table 2 Isotherm parameters for Langmuir, Freundlich and DubininRadushkevich models

\begin{tabular}{llll}
\hline & & $\mathrm{PC}$ & $\mathrm{PC}-S O_{3} \mathrm{H}$ \\
\hline \multirow{2}{*}{ Langmuir } & $Q_{\mathrm{m}}$ & $10.89 \mathrm{mg} \mathrm{g}^{-1}$ & $18.97 \mathrm{mg} \mathrm{g}^{-1}$ \\
& $b$ & $0.085 \mathrm{~L} \mathrm{mg}^{-1}$ & $4.399 \mathrm{~L} \mathrm{mg}^{-1}$ \\
& $R^{2}$ & 0.995 & 0.990 \\
Freundlich & $K_{\mathrm{F}}$ & $3.73 \mathrm{~L} \mathrm{mg}^{-1}$ & $11.69 \mathrm{~L} \mathrm{mg}^{-1}$ \\
& $N_{\mathrm{F}}$ & 5.07 & 9.89 \\
& $R^{2}$ & 0.923 & 0.757 \\
Dubinin- & $Q_{\mathrm{m}}$ & $10.24 \mathrm{mg} \mathrm{g}^{-1}$ & $18.64 \mathrm{mg} \mathrm{g}^{-1}$ \\
& $\beta$ & $4.57 \times 10^{-5} \mathrm{~mol}^{2} \mathrm{~J}^{-2}$ & $8.92 \times 10^{-9} \mathrm{~mol}^{2} \mathrm{~J}^{-2}$ \\
& $R^{2}$ & 0.972 & 0.959 \\
& $E$ & $0.11 \mathrm{~kJ} \mathrm{~mol}^{-1}$ & $7.49 \mathrm{~kJ} \mathrm{~mol}^{-1}$ \\
& & &
\end{tabular}

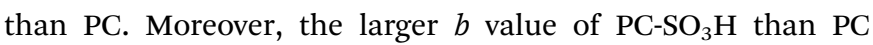
indicates the higher affinity of sulfonic acid group toward $\mathrm{Sr}^{2+}$. Therefore, addition of sulfonic acid groups onto the carbon backbone provides a positive contribution to the adsorption of $\mathrm{Sr}^{2+}$.

Other isotherm models were tested to fit the data as well, but Langmuir isotherm showed the highest accordance based on $R^{2}$ value. Freundlich isotherm curve was fitted with the equation defined as

$$
Q_{\mathrm{e}}=K_{\mathrm{F}} C_{\mathrm{e}}^{1 / N_{\mathrm{F}}}
$$

where $K_{\mathrm{F}}\left(\mathrm{L} \mathrm{mg}^{-1}\right)$ and $N_{\mathrm{F}}(-)$ are the Freundlich constants which indicate an approximate ability of adsorption.

The Dubinin-Radushkevich (D-R) curve was fitted with the equation

$$
Q_{\mathrm{e}}=Q_{\mathrm{m}} \exp \left(-\beta \varepsilon^{2}\right)
$$

where $Q_{\mathrm{e}}\left(\mathrm{mg} \mathrm{g}^{-1}\right)$ is the equilibrium adsorption, $Q_{\mathrm{m}}\left(\mathrm{mg} \mathrm{g}^{-1}\right)$ is the theoretical maximum adsorption, $\beta\left(\mathrm{mol}^{2} \mathrm{~J}^{-2}\right)$ is the $\mathrm{D}-\mathrm{R}$ isotherm coefficient related to mean free energy and $\varepsilon$ is the $\mathrm{D}-\mathrm{R}$ isotherm constant, which can be calculated by following equation: 


$$
\varepsilon=R T \ln \left(1+\frac{1}{C_{\mathrm{e}}}\right)
$$

where $R$ is the gas constant $\left(8.314 \mathrm{~J} \mathrm{~mol}^{-1} \mathrm{~K}^{-1}\right)$, and $T$ is the absolute temperature (K). The mean free energy $E\left(\mathrm{~J} \mathrm{~mol}^{-1}\right)$, which is an indicator for the type of a sorption process, can be calculated using the following relationship.

$$
E=\frac{1}{\sqrt{2 \beta}}
$$

As both $\mathrm{PC}$ and $\mathrm{PC}_{-} \mathrm{SO}_{3} \mathrm{H}$ have the $E$ value smaller than $8 \mathrm{~kJ} \mathrm{~mol}^{-1}$, physical adsorption may be the dominant mecha-

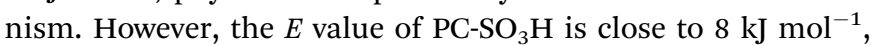
which indicates adsorption also occurred in terms of ion exchange. ${ }^{51,52}$

The improved adsorption capacity of $\mathrm{PC}-\mathrm{SO}_{3} \mathrm{H}$ is attributed to the ion exchange between $\mathrm{Sr}^{2+}$ and the proton in $\mathrm{SO}_{3} \mathrm{H}$. To validate this mechanism the exchanged amount of ions was confirmed by measuring the $\mathrm{pH}$ of the $\mathrm{Sr}^{2+}$ solution following the adsorption test. As shown in Fig. 6, the proton concentration per gram of $\mathrm{PC}^{-} \mathrm{SO}_{3} \mathrm{H}$ increased with the increasing concentration of $\mathrm{Sr}^{2+}$. For 100 and $350 \mathrm{mg} \mathrm{L}^{-1} \mathrm{Sr}^{2+}$ solutions, 0.42 and $0.62 \mathrm{mmol} \mathrm{g}^{-1}$ of protons were exchanged, respectively. These values appear reasonable considering that the adsorbed amount of $\mathrm{Sr}^{2+}$ from initial solution concentrations of 100 and $350 \mathrm{mg} \mathrm{L}^{-1}$ equalled $0.22 \mathrm{mmol} \mathrm{g}^{-1}$ and $0.25 \mathrm{mmol} \mathrm{g}^{-1}$, respectively. These data not only support the mechanism of $\mathrm{Sr}^{2+}$

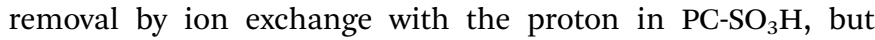
also quantify the exchange ratio of proton to $\mathrm{Sr}^{2+}$ to be approximately 2 .

Ion exchange between $\mathrm{Sr}^{2+}$ and proton was confirmed in XPS results as well. The clear peak shift was observed in comparison between $\mathrm{O}$ 1s spectra of pristine $\mathrm{PC}-\mathrm{SO}_{3} \mathrm{H}$ and $\mathrm{Sr}^{2+}$-adsorbed PC$\mathrm{SO}_{3} \mathrm{H}$ (Fig. S3(a) $\dagger$ ). This shift is caused by the replacement of $\mathrm{H}^{+}$ into $\mathrm{Sr}^{2+}$ which is bonded to oxygen atoms. In addition, $\mathrm{Sr} 3 \mathrm{~d}$ peaks obtained from $\mathrm{PC}-\mathrm{SO}_{3} \mathrm{H}$ after adsorption (Fig. S3(b) $\dagger$ )

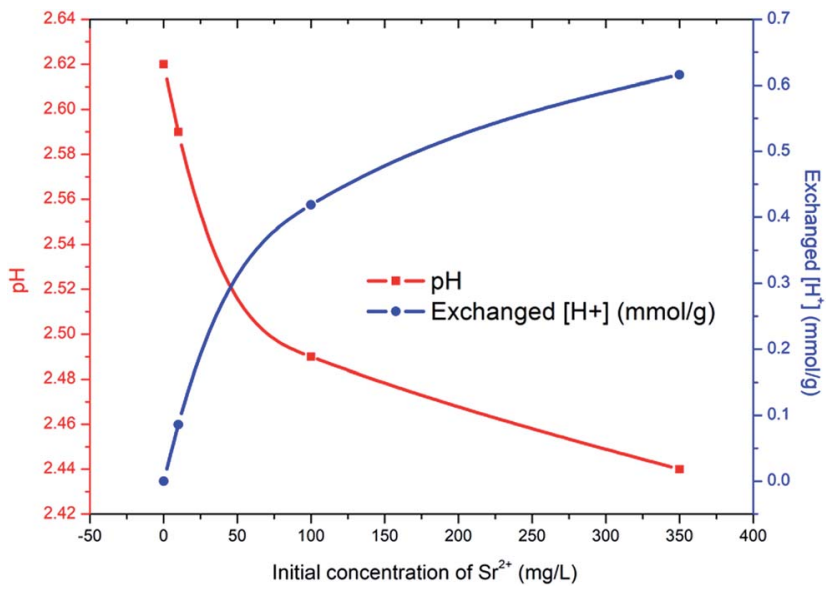

Fig. 6 Measured $\mathrm{pH}$ (red line and square symbol) and exchanged amount of proton per gram of $\mathrm{PC}-\mathrm{SO}_{3} \mathrm{H}$ (blue line and circle symbol) of $\mathrm{Sr}^{2+}$ solutions with the initial concentrations of $0,10,100$ and $350 \mathrm{mg} \mathrm{L}^{-1}$. show peak shift compared to element Sr. That is due to the bond between $\mathrm{Sr}$ and electronegative moiety of oxygen.

The enhanced $\mathrm{Sr}^{2+}$ adsorption performance of the synthesized $\mathrm{PC}-\mathrm{SO}_{3} \mathrm{H}$ was compared to previously reported values for carbon-based adsorbents. As shown in Table 3, $\mathrm{PC}^{-\mathrm{SO}_{3} \mathrm{H}}$ exhibits outstanding or equivalent performance among carbonbased adsorbents including CNTs and graphenes which often require complex synthesis routes. As such, sulfonation of carbon materials is a viable facile method to produce economical adsorbents for $\mathrm{Sr}^{2+}$.

Furthermore, the $\mathrm{Sr}^{2+}$ removal efficiency from aqueous solutions of low $\mathrm{Sr}^{2+}$ concentration is an important performance parameter when evaluating adsorbents, since these often represent conditions encountered in the environment.

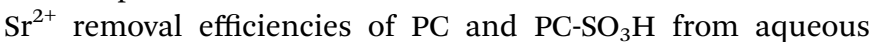
solutions containing $5 \mathrm{mg} \mathrm{L}^{-1}$ and $10 \mathrm{mg} \mathrm{L}^{-1} \mathrm{Sr}^{2+}$ are shown in Table 4. For $5 \mathrm{mg} \mathrm{L}{ }^{-1} \mathrm{Sr}^{2+}$ solution, the removal efficiencies

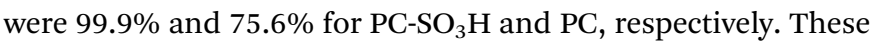
efficiencies reduced to $97.6 \%$ and $37.8 \%$ when the particles were dispersed in $10 \mathrm{mg} \mathrm{\textrm {L } ^ { - 1 }} \mathrm{Sr}^{2+}$ solution. Hence, the data demonstrates the high removal efficiency of $\mathrm{PC}^{-\mathrm{SO}_{3} \mathrm{H} \text { when }}$ adsorbing trace amounts of $\mathrm{Sr}^{2+}$ in aqueous solutions.

The distribution coefficient $\left(K_{\mathrm{d}}, \mathrm{mL} \mathrm{g}^{-1}\right)$, which represents the affinity between $\mathrm{Sr}^{2+}$ and adsorbent, is another indicator to verify the performance of adsorbents. $K_{\mathrm{d}}$ is calculated as follows:

$$
K_{\mathrm{d}}=\frac{\left(C_{0}-C_{\mathrm{e}}\right)}{C_{\mathrm{e}}}\left(\frac{V}{m}\right)
$$

where $C_{0}$ and $C_{\mathrm{e}}\left(\mathrm{mg} \mathrm{\textrm {L } ^ { - 1 }}\right)$ are the initial and equilibrium concentrations of $\mathrm{Sr}^{2+}, V(\mathrm{~mL})$ is the volume of solution and $m$ (g) is the weight of adsorbents. The calculated $K_{\mathrm{d}}$ values shown in Table 4 demonstrate that $\mathrm{PC}-\mathrm{SO}_{3} \mathrm{H}$ has a much higher affinity toward $\mathrm{Sr}^{2+}$ than PC. Typically, the $K_{\mathrm{d}}$ value on the order of $10^{4}$ or $10^{5}$ is judged as an excellent level. ${ }^{54,55}$ Thus, the calculated $K_{\mathrm{d}}$

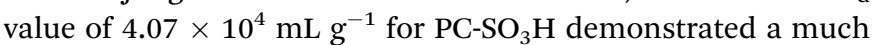
higher selectivity toward $\mathrm{Sr}^{2+}$ than PC.

Normally removal efficiency of ions is affected by the $\mathrm{pH}$ of liquid. Therefore confirmation of adsorbents' performance in various $\mathrm{pH}$ conditions is important to ensure their applicability

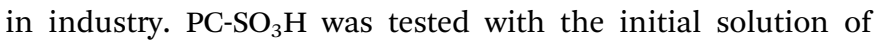
varying $\mathrm{pH}$ conditions from 2 to 12 . As show in Fig. 7, $\mathrm{PC}^{-\mathrm{SO}_{3} \mathrm{H}}$

Table 3 Comparison of adsorption capacity of $\mathrm{PC}-\mathrm{SO}_{3} \mathrm{H}$ with other carbon-based adsorbents

\begin{tabular}{ll}
\hline Materials & $\begin{array}{l}\text { Adsorption capacity } \\
\left(\mathrm{mg} \mathrm{g}^{-1}\right)\end{array}$ \\
\hline $\mathrm{PC}^{\circ} \mathrm{SO}_{3} \mathrm{H}$ & 18.97 (this work) \\
Oxidatively modified carbon & 0.48 (ref. 24) \\
Multi-walled CNT/iron oxide & 9.18 (ref. 25) \\
Graphene oxide & 23.66 (ref. 26) \\
Activated carbon & 12.11 (ref. 27) \\
MWCNTs-SMP hybrids & 14.92 (ref. 53) \\
Oxidized MWCNTs & 10.87 (ref. 53)
\end{tabular}

${ }^{a}$ Theoretical maximum $\mathrm{Sr}^{2+}$ adsorption capacity calculated by the Langmuir isotherm model. 
Table 4 Removal efficiency and $K_{d}$ values for $\mathrm{PC}$ and $\mathrm{PC}-\mathrm{SO}_{3} \mathrm{H}$

\begin{tabular}{lll}
\hline & $\mathrm{PC}$ & ${\mathrm{PC}-\mathrm{SO}_{3} \mathrm{H}}$ \\
\hline $\begin{array}{l}\text { Removal efficiency at } \\
5 \mathrm{mg} \mathrm{L}^{-1}\end{array}$ & $75.6 \%$ & $99.9 \%$ \\
Removal efficiency at $_{10 \mathrm{mg} \mathrm{L}^{-1}}$ & $37.8 \%$ & $97.6 \%$ \\
$K_{\mathrm{d}}$ at $10 \mathrm{mg} \mathrm{L}^{-1}\left(\mathrm{~mL} \mathrm{~g}^{-1}\right)$ & $6.08 \times 10^{2} \mathrm{~mL} \mathrm{~g}^{-1}$ & $4.07 \times 10^{4} \mathrm{~mL} \mathrm{~g}^{-1}$
\end{tabular}

shows high removal efficiency both in acidic (pH 4) as well as basic conditions ( $\mathrm{pH} 10)$. However, it shows reduced adsorption performance in extreme acidic media with $\mathrm{pH} 2$. On the other hands, adsorption capacity was increased by $99 \%$ in extremely basic solution with $\mathrm{pH} 12$. That may be because the mechanism

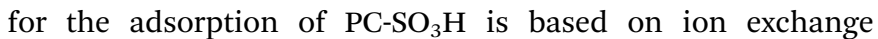
between proton and strontium, which may be hindered in acidic conditions and promoted in basic conditions.

Along with the removal efficiency the $\mathrm{Sr}^{2+}$ adsorption kinetics, more specifically the initial adsorption rate, is an important performance parameter. The adsorption kinetics of both carbon-based adsorbents was quantified using the following pseudo-second-order kinetics model:

$$
\frac{t}{Q_{t}}=\frac{1}{k_{2} Q_{\mathrm{e}}{ }^{2}}+\frac{t}{Q_{\mathrm{e}}}
$$

where $Q_{t}\left(\mathrm{mg} \mathrm{g}^{-1}\right)$ is the amount of $\mathrm{Sr}^{2+}$ adsorbed at time $t(\mathrm{~min})$, $Q_{\mathrm{e}}\left(\mathrm{mg} \mathrm{g}^{-1}\right)$ is the amount of $\mathrm{Sr}^{2+}$ adsorbed at equilibrium, and $k_{2}\left(\mathrm{~g}\left(\mathrm{mg}^{-1} \mathrm{~min}^{-1}\right)\right)$ is the rate constant. Each particle sample was dispersed in $20 \mathrm{mg} \mathrm{L}^{-1} \mathrm{Sr}^{2+}$ solution at a particle concentration of $1 \mathrm{~g} \mathrm{~L}^{-1}$. The suspension was shaken and samples periodically removed, and the concentration of $\mathrm{Sr}^{2+}$ normalized to initial concentration is shown in Fig. 8. The fitting parameters, $Q_{\mathrm{e}}$ and $k_{2}$, of the pseudo-second-order rate equation are

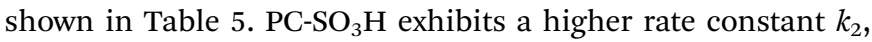
indicating rapid adsorption when compared to PC, along with an equilibrium adsorption capacity which is 3.52 times greater than PC.

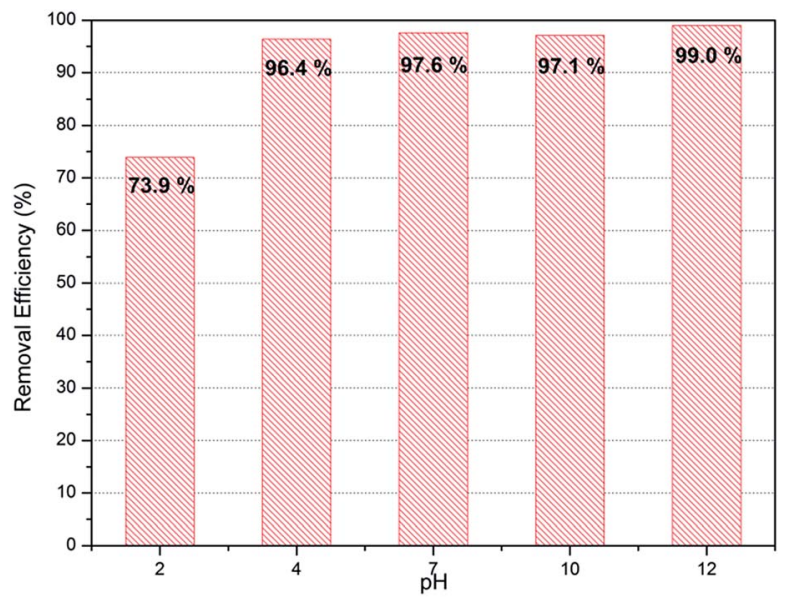

Fig. $7 \mathrm{Sr}^{2+}$ removal efficiency of $\mathrm{PC}-\mathrm{SO}_{3} \mathrm{H}$ in various $\mathrm{pH}$ conditions $\left(C_{0}\right.$ for $\left.\mathrm{Sr}^{2+}=10 \mathrm{mg} \mathrm{L}^{-1}\right)$.

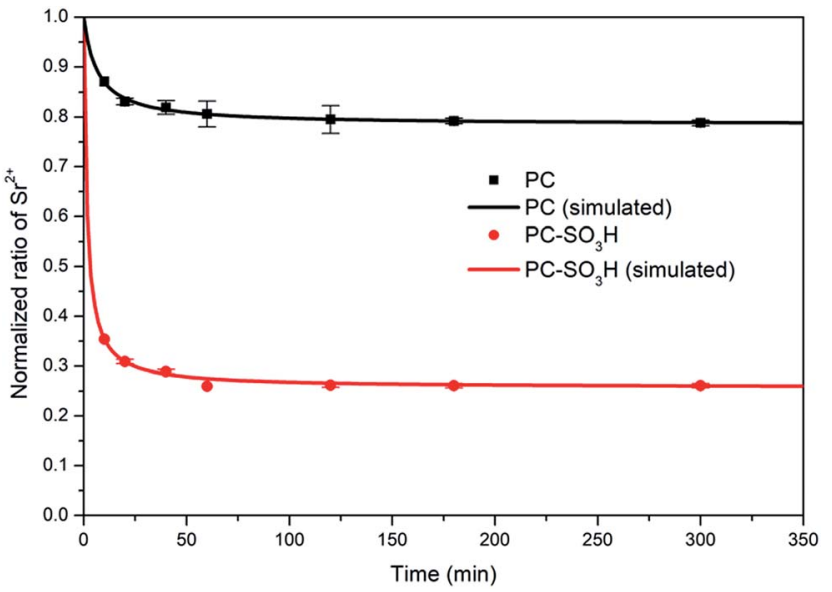

Fig. 8 Normalized ratio of $\mathrm{Sr}^{2+}\left(C_{0}=20 \mathrm{mg} \mathrm{L}^{-1}\right)$ as a function of time. Lines represent the fits of the pseudo-second order rate equation.

As demonstrated, the sulfonic acid groups of $\mathrm{PC}^{-\mathrm{SO}_{3} \mathrm{H}}$ promote the enhancement of $\mathrm{Sr}^{2+}$ removal performance (adsorption kinetics and capacity) when compared to PC. Moreover, the sulfonic acid groups improve the selectivity of the carbon-based adsorbent for trace amounts of $\mathrm{Sr}^{2+}$ when in the presence of excess competing ions, see Fig. 9. When dispersed

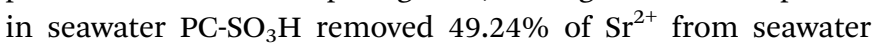
having $10 \mathrm{mg} \mathrm{L}^{-1} \mathrm{Sr}^{2+}$ (Fig. 9(a)). Although the adsorption efficiency from seawater is much lower than pure water condition ( $97.6 \%$ for $10 \mathrm{mg} \mathrm{L}^{-1} \mathrm{Sr}^{2+}$ ) due to the blocking effect caused by excess amount of other competing ions, however, PC removed only $13.37 \%$ of $\mathrm{Sr}^{2+}$ under the same condition. It should be noted that $\mathrm{PC}_{-} \mathrm{SO}_{3} \mathrm{H}$ is much more effective at removing $\mathrm{Sr}^{2+}$ from complex ionic solutions such as seawater. To better understand the effect of competing ions, a model solution consisting of $10 \mathrm{mg} \mathrm{L}^{-1} \mathrm{Sr}^{2+}, 400 \mathrm{mg} \mathrm{L}^{-1} \mathrm{~K}^{+}, 10000 \mathrm{mg} \mathrm{L}^{-1} \mathrm{Na}^{+}$, $200 \mathrm{mg} \mathrm{L}^{-1} \mathrm{Ca}^{2+}$ and $1300 \mathrm{mg} \mathrm{L}^{-1} \mathrm{Mg}^{2+}$ was used to re-evaluate the effect of competing ions. Compared to the $\mathrm{Sr}^{2+}$ adsorption from the $\mathrm{Sr}^{2+}$ diluted solution, the adsorption of $\mathrm{Na}^{+}, \mathrm{K}^{+}$and $\mathrm{Mg}^{2+}$ is nearly negligible. Interestingly, removal efficiencies of PC- $\mathrm{SO}_{3} \mathrm{H}$ towards $\mathrm{K}^{+}, \mathrm{Na}^{+}$and $\mathrm{Mg}^{2+}$ were even reduced compared to those of PC as shown in Fig. 9(b). It means that sulfonation not only improves the affinity towards $\mathrm{Sr}^{2+}$, but also inhibits the adsorption of competing ions at the same time. Especially for $\mathrm{Na}^{+}$, which accounts for the biggest part of cations in seawater, sulfonation in $\mathrm{PC}_{-} \mathrm{SO}_{3} \mathrm{H}$ can reduce $\mathrm{Na}$ removal by about 1/30 compared to the PC case. Bivalent $\mathrm{Sr}^{2+}$ can be more selectively bound to the sulfonic acid sites than monovalent

Table 5 Kinetic parameters for fitting pseudo-second-order kinetics curves

\begin{tabular}{lll}
\hline & $\mathrm{PC}$ & ${\mathrm{PC}-\mathrm{SO}_{3} \mathrm{H}}$ \\
\hline$Q_{\mathrm{e}}$ & $4.317 \mathrm{mg} \mathrm{g}^{-1}$ & $15.195 \mathrm{mg} \mathrm{g}^{-1}$ \\
$k_{2}$ & $\begin{array}{l}0.03532 \mathrm{~g} \\
\left(\mathrm{mg}^{-1} \mathrm{~min}^{-1}\right)\end{array}$ & $0.0444{\mathrm{~g}\left(\mathrm{mg}^{-1} \mathrm{~min}^{-1}\right)}^{2}$ \\
$R^{2}$ & 0.9938 & 0.9861
\end{tabular}




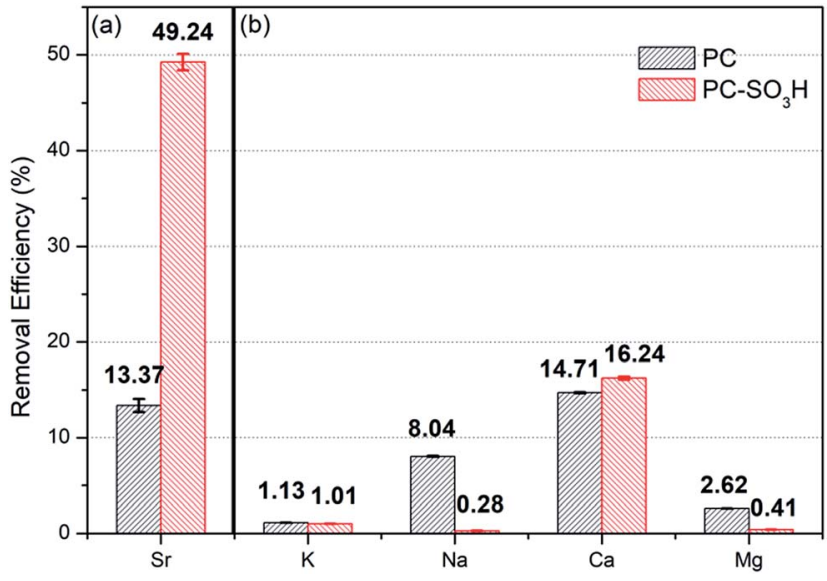

Fig. 9 Removal efficiency of (a) $\mathrm{Sr}^{2+}$ in seawater and (b) competitive ions $\left(\mathrm{K}^{+}, \mathrm{Na}^{+}, \mathrm{Ca}^{2+}\right.$ and $\left.\mathrm{Mg}^{2+}\right)$ in model solution $\left(\mathrm{C}_{0}=400 \mathrm{mg} \mathrm{L}^{-1}\right.$ for $\mathrm{K}, 10000 \mathrm{mg} \mathrm{L}^{-1}$ for $\mathrm{Na}, 200 \mathrm{mg} \mathrm{L}^{-1}$ for $\mathrm{Ca}$ and $1300 \mathrm{mg} \mathrm{L}^{-1}$ for $\mathrm{Mg}$ ) for $\mathrm{PC}$ and $\mathrm{PC}-\mathrm{SO}_{3} \mathrm{H}$.

$\mathrm{Na}^{+}$. That is an encouraging result and the functionalization of carbon with sulfonic acid group is an effective way for the selective removal of $\mathrm{Sr}^{2+}$ in contaminated water.

\section{Conclusions}

We have introduced a facile method to functionalize $\mathrm{CO}_{2}$ derived porous carbon materials with $\mathrm{SO}_{3} \mathrm{H}$ group for the $\mathrm{Sr}^{2+}$ removal in aqueous solutions. Due to the ion exchange between the proton in $\mathrm{SO}_{3} \mathrm{H}$ group and $\mathrm{Sr}^{2+}$ in the solution, synthesized PC-SO $\mathrm{S}_{3} \mathrm{H}$ shows enhanced $\mathrm{Sr}^{2+}$ adsorption performance in terms of removal capacity, selectivity and kinetics. In addition, PC-SO ${ }_{3} \mathrm{H}$ provides outstanding selectivity towards $\mathrm{Sr}^{2+}$ even in aqueous solutions with excess amounts of competing ions though its exact mechanism is still needed to be studied. This work suggests a potential of functionalized carbons as adsorbents to remove the traced amounts of $\mathrm{Sr}^{2+}$ ions in contaminated water with nuclear wastes.

\section{Conflicts of interest}

There are no conflicts to declare.

\section{Acknowledgements}

The authors are grateful for the financial support from the UK Korea Joint Research Program through NRF grants (NRF2015M2A7A1000219) funded by the Ministry of Science, ICT, and Future Planning. D. Harbottle acknowledges the support of Engineering and Physical Sciences Research Council grant number EP/M026426/1.

\section{Notes and references}

1 I. E. Agecy, Key world energy statistics, International Energy Agecy, 2016.
2 Y. Kim, Y. K. Kim, S. Kim, D. Harbottle and J. W. Lee, Chem. Eng. J., 2017, 313, 1042-1050.

3 S. Chegrouche, A. Mellah and M. Barkat, Desalination, 2009, 235, 306-318.

4 B. O. Boehm, S. Rosinger, D. Belyi and J. W. Dietrich, N. Engl. J. Med., 2011, 365, 676-678.

5 Y. K. Kim, Y. Kim, S. Kim, D. Harbottle and J. W. Lee, J. Environ. Chem. Eng., 2017, 5, 975-986.

6 A. Ahmadpour, M. Zabihi, M. Tahmasbi and T. R. Bastami, J. Hazard. Mater., 2010, 182, 552-556.

7 A. Shahzad, W. Miran, K. Rasool, M. Nawaz, J. Jang, S.-R. Lim and D. S. Lee, RSC Adv., 2017, 7, 9764-9771.

8 M. R. Awual, T. Yaita, T. Taguchi, H. Shiwaku, S. Suzuki and Y. Okamoto, J. Hazard. Mater., 2014, 278, 227-235.

9 H.-M. Yang, S.-C. Jang, S. B. Hong, K.-W. Lee, C. Roh, Y. S. Huh and B.-K. Seo, J. Alloys Compd., 2016, 657, 387-393.

10 H. Yang, L. Sun, J. Zhai, H. Li, Y. Zhao and H. Yu, J. Mater. Chem. A, 2014, 2, 326-332.

11 Z. Ning, M. Ishiguro, L. K. Koopal, T. Sato and J. i. Kashiwagi, Soil Sci. Plant Nutr., 2017, 63, 14-17.

12 D. Liu and H. Zheng, J. Radioanal. Nucl. Chem., 2017, 311, 1883-1890.

13 B. Yıldız, H. N. Erten and M. Kış, J. Radioanal. Nucl. Chem., 2011, 288, 475-483.

14 H. Zhang, Y. K. Kim, T. N. Hunter, A. P. Brown, J. W. Lee and D. Harbottle, J. Mater. Chem. A, 2017, 5, 15130-15143.

15 Y. F. Jia, B. Xiao and K. M. Thomas, Langmuir, 2002, 18, 470478.

16 S. Biniak, M. Pakuła, G. S. Szymański and A. Świątkowski, Langmuir, 1999, 15, 6117-6122.

17 X. Mao, Z. Yan, T. Sheng, M. Gao, H. Zhu, W. Xiao and D. Wang, Carbon, 2017, 111, 162-172.

18 Y. Zhang, X. Lin, S. Hu, X. Zhang and X. Luo, RSC Adv., 2016, 6, 73959-73973.

19 Y. Song, H. Ou, W. Bian, Y. Zhang, J. Pan, Y. Liu and W. Huang, J. Inorg. Organomet. Polym. Mater., 2013, 23, 1325-1334.

20 A. Y. Zhang, E. Kuraoka and M. Kumagai, Sep. Purif. Technol., 2006, 50, 35-44.

21 H. Liu, A. Yonezawa, K. Kumagai, M. Sano and T. Miyake, J. Mater. Chem. A, 2015, 3, 1562-1568.

22 T. Li, F. He and Y. Dai, J. Radioanal. Nucl. Chem., 2016, 310, 1139-1145.

23 L. K. Dhandole, J. Ryu, J.-M. Lim, B.-T. Oh, J. H. Park, B.-G. Kim and J. S. Jang, RSC Adv., 2016, 6, 98449-98456.

24 A. Khannanov, V. V. Nekljudov, B. Gareev, A. Kiiamov, J. M. Tour and A. M. Dimiev, Carbon, 2017, 115, 394-401.

25 C. Chen, J. Hu, D. Shao, J. Li and X. Wang, J. Hazard. Mater., 2009, 164, 923-928.

26 A. Y. Romanchuk, A. S. Slesarev, S. N. Kalmykov, D. V. Kosynkin and J. M. Tour, Phys. Chem. Chem. Phys., 2013, 15, 2321-2327.

27 E. Kaçan and C. Kütahyalı, J. Anal. Appl. Pyrolysis, 2012, 97, 149-157.

28 A. Y. Romanchuk, A. S. Kuzenkova, A. S. Slesarev, J. M. Tour and S. N. Kalmykov, Solvent Extr. Ion Exch., 2016, 34, 594602. 
29 E. W. Shin and R. M. Rowell, Chemosphere, 2005, 60, 10541061.

30 V. V. Kulkarni, A. K. Golder and P. K. Ghosh, RSC Adv., 2016, 6, 5341-5349.

31 Z.-B. Zhang, X.-F. Yu, X.-H. Cao, R. Hua, M. Li and Y.-H. Liu, J. Radioanal. Nucl. Chem., 2014, 301, 821-830.

32 B. Aguila, D. Banerjee, Z. Nie, Y. Shin, S. Ma and P. K. Thallapally, Chem. Commun., 2016, 52, 5940-5942.

33 Y. K. Kim, T. Kim, Y. Kim, D. Harbottle and J. W. Lee, J. Hazard. Mater., 2017, 340, 130-139.

34 J. Zhang and J. W. Lee, Carbon, 2013, 53, 216-221.

35 A. Byeon, J. Park, S. Baik, Y. Jung and J. W. Lee, J. Mater. Chem. A, 2015, 3, 5843-5849.

36 Y. Kim, W. Lee, G. M. Kim and J. W. Lee, $R S C A d v .$, 2016, 6, 54889-54897.

37 S. Baik, B. L. Suh, A. Byeon, J. Kim and J. W. Lee, J. CO Util., 2017, 20, 73-80.

38 H. Yu, Y. Jin, Z. Li, F. Peng and H. Wang, J. Solid State Chem., 2008, 181, 432-438.

39 K. Nakajima and M. Hara, ACS Catal., 2012, 2, 1296-1304.

40 W. W. Mar and E. Somsook, Procedia Eng., 2012, 32, 212-218.

41 B. Xie, L. Hong, P. Chen and B. Zhu, Polym. Bull., 2015, 73, 891-908.

42 S. Madakbaş, E. Çakmakçı and M. V. Kahraman, Thermochim. Acta, 2013, 552, 1-4.

43 F. Liu, J. Sun, L. Zhu, X. Meng, C. Qi and F.-S. Xiao, J. Mater. Chem., 2012, 22, 5495.
44 X. Li, S. P. Lau, L. Tang, R. Ji and P. Yang, Nanoscale, 2014, 6, 5323-5328.

45 H. Huang, Y.-C. Lu, A.-J. Wang, J.-H. Liu, J.-R. Chen and J.-J. Feng, RSC Adv., 2014, 4, 11872.

46 Q. Xu, P. Pu, J. Zhao, C. Dong, C. Gao, Y. Chen, J. Chen, Y. Liu and H. Zhou, J. Mater. Chem. A, 2015, 3, 542-546.

47 B. P. Vinayan, Z. Zhao-Karger, T. Diemant, V. S. Chakravadhanula, N. I. Schwarzburger, M. A. Cambaz, R. J. Behm, C. Kubel and M. Fichtner, Nanoscale, 2016, 8, 3296-3306.

48 Q. Xu, Y. Liu, C. Gao, J. Wei, H. Zhou, Y. Chen, C. Dong, T. S. Sreeprasad, N. Li and Z. Xia, J. Mater. Chem. C, 2015, 3, 9885-9893.

49 U. Siemeling, H. Memczak, C. Bruhn, F. Vogel, F. Trager, J. E. Baio and T. Weidner, Dalton Trans., 2012, 41, 29862994.

50 C. Xu, Q. Han, Y. Zhao, L. Wang, Y. Li and L. Qu, J. Mater. Chem. A, 2015, 3, 1841-1846.

51 B. Ma, S. Oh, W. S. Shin and S.-J. Choi, Desalination, 2011, 276, 336-346.

52 Y. Park, Y.-C. Lee, W. S. Shin and S.-J. Choi, Chem. Eng. J., 2010, 162, 685-695.

53 N. Asadollahi, R. Yavari and H. Ghanadzadeh, J. Radioanal. Nucl. Chem., 2015, 303, 2445-2455.

54 H. Yang, H. Li, J. Zhai, L. Sun, Y. Zhao and H. Yu, Chem. Eng. J., 2014, 246, 10-19.

55 J. L. Mertz, Z. H. Fard, C. D. Malliakas, M. J. Manos and M. G. Kanatzidis, Chem. Mater., 2013, 25, 2116-2127. 